\title{
Gastric Gastrointestinal Stromal Tumor
}

National Cancer Institute

\section{Source}

National Cancer Institute. Gastric Gastrointestinal Stromal Tumor. NCI Thesaurus. Code C5806.

A gastrointestinal stromal tumor that arises from the stomach. It covers a spectrum of benign to malignant soft tissue neoplasms and includes most gastric smooth muscle tumors, leiomyoblastomas, and tumors formerly called gastrointestinal autonomic nerve tumors. 